\title{
Ministério Público Federal e Polícia Federal: uma análise sobre os conteúdos das páginas oficiais no Facebook $^{1}$
}

\author{
Carla Avanzi ${ }^{2}$ \\ Recebido em setembro de 2020 \\ Aceito em dezembro de 2020
}

\begin{abstract}
RESUMO
O presente artigo analisou as estratégias de comunicação utilizadas pelas instituições envolvidas na operação Lava Jato, Ministério Público Federal e Polícia Federal no Facebook, a fim de compreender um dos aspectos da luta simbólica por poder pelas instituições da burocracia. Com esse estudo, buscou-se responder às seguintes questões: As duas instituições envolvidas na utilizam o Facebook como estratégia de comunicação? A corrupção é o principal tema abordado ou outras temáticas são priorizadas nas publicações das instituições? A reação dos usuários nas páginas é semelhante para as duas instituições? Para atingir os fins almejados, foi realizado um levantamento das postagens nas páginas oficiais do Facebook das duas instituições durante o ano de 2018, com o propósito de averiguar a quantidade, frequência e conteúdo das publicações. Constatou-se que embora as duas instituições utilizem rotineiramente o Facebook, suas estratégias na rede social são distintas. Enquanto a Polícia Federal prioriza publicações relacionadas à capacidade institucional, o Ministério Público destaca assuntos relacionados às suas atribuições constitucionais. Além disso, ainda que integrem a mesma operação com grande destaque midiático, as publicações sobre corrupção e as reações dos usuários distinguem consideravelmente nas páginas das duas instituições.
\end{abstract}

Palavras-chave: Facebook; Polícia Federal; Ministério Público Federal; lutas simbólicas.

\section{Federal Public Ministry and Federal Police: an analysis on the contents of the oficial facebook pages}

\begin{abstract}
This article analyzed the communication strategies used by the institutions involved in the Lava Jato operation, the Federal Public Ministry and the Federal Police on Facebook, in order to understand one aspect of the symbolic struggle for power by the bureaucratic institutions. With this study, we sought to answer the following questions: Do the two institutions involved in using Facebook as a communication strategy? Is corruption the main topic addressed or are other themes prioritized in the institutions' publications? Is the reaction of users on the pages similar for the two institutions? In order to achieve the desired goals, a survey of posts on the official Facebook pages of the two institutions was carried out during 2018, with the purpose of ascertaining the quantity, frequency, and content of publications. It was
\end{abstract}

\footnotetext{
${ }^{1}$ Uma versão preliminar deste artigo foi apresentada no X Seminário Nacional Sociologia \& Política, na UFPR em 2019. Agradecemos os valiosos comentários dos debatedores que contribuíram para o aperfeiçoamento do trabalho.

${ }^{2}$ Mestranda em Sociologia - UEL. Graduada em Direito - UEL. Especialista em Direito e Processo Penal. Especialista em Direito Constitucional Contemporâneo. Este estudo foi financiando com recursos da CAPES. E-mail: carla_avanzi@hotmail.com.
} 
found that although the two institutions routinely use Facebook, their strategies on the social network are different. While the Federal Police prioritizes publications related to institutional capacity, the Public Ministry highlights issues related to its constitutional attributions. In addition, even though they are part of the same operation with great media attention, the publications on corruption and the reactions of users differ considerably on the pages of the two institutions.

Keywords: Facebook; Federal Police; Federal Public Prosecution Service; symbolic struggles.

\section{Introdução}

presente estudo buscou investigar as estratégias de comunicação utilizadas pelas instituições de persecução penal de âmbito federal, Ministério Público Federal (MPF) e Polícia Federal (PF) nas mídias sociais, a fim de elucidar uma das faces da luta simbólica por poder pelas instituições da burocracia no âmbito estatal. Assim, foram coletados dados das publicações nas páginas oficiais do Facebook das duas instituições durante o ano de 2018, a fim de averiguar a quantidade, frequência e conteúdo das publicações.

Os novos meios de comunicação têm gerado a necessidade de adaptação por parte das instituições burocráticas, que buscam atrair apoio popular no cumprimento de suas atividades. Assim, cada vez mais as estratégias de comunicação utilizadas têm se diversificado, com a utilização de meios eletrônicos, além dos meios de comunicação já tradicionalmente utilizados, como entrevistas para jornais e notas públicas para a imprensa, com a finalidade de mobilizar as massas para reforçar seus interesses institucionais.

A estratégia utilizada na Operação Lava Lato, realizada pela Polícia Federal (PF) em conjunto com o Ministério Público Federal (MPF), é uma das principais referências de grande mobilização da mídia pelas instituições, na defesa de suas atividades e busca de apoio popular. Além disso, a operação Lava Jato se constitui como objeto atípico de utilização da mídia por instituições, visto que outras operações anteriores não obtiveram tanto sucesso na mobilização popular. Assim, as duas instituições envolvidas na operação serão objeto de análise na pesquisa.

O Ministério Público Federal e a Polícia Federal, ainda que não sejam formalmente subordinados ao poder judiciário, são órgãos estatais de persecução penal que integram o sistema de justiça, visto que investigam e denunciam os crimes de 
corrupção. Ao Ministério Público, dotado de independência funcional, compete "promover, privativamente, a ação penal pública, na forma da lei” (Constituição Federal, art. 129, I). A Polícia Federal, ainda que vinculada ao poder executivo, tem o dever de "apurar infrações penais contra a ordem política e social ou em detrimento de bens, serviços e interesses da União ou de suas entidades autárquicas e empresas públicas” (Constituição Federal, art. 144, §1º, I), de forma que sua atividade está intrinsecamente vinculada à apuração dos crimes de corrupção em que os agentes dos poderes estejam envolvidos. Para fins de realização desta pesquisa, essas duas instituições serão consideradas como órgãos integrantes do sistema de justiça, lato sensu.

A atuação dos órgãos do sistema de justiça no combate à corrupção está inserida em um contexto de lutas simbólicas pelo poder do Estado (BOURDIEU, 2007). Esses instrumentos são distribuídos desigualmente entre os atores, de forma que há uma constante necessidade de ratificação do poder, como forma de impor seu posicionamento institucional sobre os demais atores do sistema. As estratégias de comunicação são mobilizadas para aumentar o poder simbólico, e garantir a continuidade do cumprimento de suas funções institucionais.

Neste sentido, as estratégias utilizadas muitas vezes determinam o grau de apoio recebido da população, ratificando ou não a legitimidade de atuação no cumprimento de suas funções. O Ministério Público Federal e a Polícia Federal têm uma função essencial no processo de combate à corrupção, visto que são órgãos de caráter acusatório do sistema judiciário e que estão constantemente sujeitos à ataques dos demais poderes à sua legitimidade para atuar. Alguns estudos anteriores analisaram aspectos de cada uma dessas instituições com a mídia, como trabalho de Isabela Veiga (2009) sobre a construção da reputação institucional da Polícia Federal, ou o trabalho de Cláudia Lemos e Antônio Barros (2016) sobre o poder de agência do Ministério Público na arena midiática. No entanto, há uma lacuna de estudos sobre a utilização de mídias sociais pelas duas instituições com grande destaque midiático no combate á corrupção nos últimos anos.

No âmbito dos possíveis conflitos decorrentes do sistema burocrático relacionados por Max Weber (1986), a busca por legitimidade se apresenta como um dos principais desafios. Sobre as disputas políticas, Pierre Bourdieu (2007) destaca que a 
busca pela legitimidade do poder constitui uma luta simbólica, em que se buscam os instrumentos de legitimação que decorrem do poder estatal. Esses instrumentos são distribuídos desigualmente entre os atores, havendo uma constante busca de ratificação do poder, como forma de impor seu posicionamento institucional sobre os demais atores do sistema. Neste sentido, têm-se a hipótese que a utilização dos aparatos midiáticos pelos órgãos dos sistemas judiciários tem por objetivo angariar apoio popular para legitimar suas ações. As estratégias de comunicação são mobilizadas para aumentar o poder simbólico decorrente do Estado, e garantir a continuidade do cumprimento de suas funções.

Dentre essas estratégias utilizadas, as redes sociais online se constituem um importante instrumento de comunicação para esta finalidade, visto que as pessoas utilizam a rede para "formar novos padrões de interação e criar novas formas de sociabilidade e novas organizações sociais" (RECUERO, 2009, p. 89). Esta pesquisa visa elucidar um dos aspectos da comunicação utilizada pelas instituições, a partir da comparação de suas páginas oficias no Facebook, com o propósito de responder aos questionamentos seguintes.

As duas instituições envolvidas na operação Lava Jato utilizam o Facebook como estratégia de comunicação? Tem-se a hipótese que, por meio de estratégias diversas nas mídias sociais, dentre elas o Facebook, as instituições visam angariar apoio popular para a realização de suas atribuições institucionais, com a utilização de publicações frequentes que atraiam a atenção do público, como um aspecto da competição no ciberespaço. A corrupção é o principal tema abordado ou outras temáticas são priorizadas nas publicações? Como a operação Lava Jato possui grande repercussão, outra hipótese é que as instituições nela envolvidas visam divulgar assuntos relacionados ao combate à corrupção, a fim de ratificar sua atuação nesta seara. A reação dos usuários nas páginas é semelhante para as duas instituições? Como as duas instituições estão envolvidas na operação, que ganhou grande destaque midiático, uma hipótese é que os usuários reajam com a mesma frequência nas páginas das duas instituições. Para atingir os objetivos almejados, foi realizado um levantamento das publicações nas páginas oficiais das duas instituições, Ministério Público Federal e Polícia Federal, durante o ano 
de 2018, verificando-se a frequência e quantidade de postagens, bem como a análise do conteúdo das publicações.

\section{Metodologia}

As páginas oficiais no Facebook do MPF e PF constituem importante fonte de informações visto que representam um dos principais canais de comunicação dessas instituições com a sociedade, juntamente com as coletivas de imprensa e outras entrevistas concedidas. Além disso, uma das peculiaridades desta fonte de informação é a possibilidade de aferir, ao menos e alguns aspectos, a reação dos receptores da informação, mensurando curtidas, comentários e compartilhamentos (reações específicas do Facebook), o que não ocorre nos meios de comunicação tradicionais, em que são necessárias técnicas mais sofisticadas para apurar essa reação. Ainda que as mídias sociais constituam um canal limitado de comunicação, visto que a informação é transmitida apenas aos seus usuários, elas têm ganhado cada vez mais destaque por sua capacidade de atingir públicos que não se interessam por outros canais midiáticos, além da possibilidade de interação entre os usuários e a grande rapidez com que a informação pode ser transmitida.

Para Jackson Sá-Silva, Cristóvão Almeida e Joel Guindani (2009) o conceito de documento transcende o conceito de texto escrito ou impresso, agregando outros tipos de fontes não escritas, como filmes, vídeos, slides, fotografias, dentre outros. Sá-Silva, Almeida e Guindani, ao discorrerem sobre a melhor nomenclatura para o estudo sobre documentos, depreenderam que "a pesquisa documental é um procedimento que se utiliza de métodos e técnicas para a apreensão, compreensão e análise de documentos dos mais variados tipos" (2009, p. 5). Neste sentido, a análise de publicações nas mídias sociais pode ser considerada uma análise de documentos, pois representam manifestações legítimas e registradas das instituições em foco, sem interferência do pesquisador.

O corpus da pesquisa foi composto por todas as postagens nas páginas oficiais no Facebook do MPF e PF, compreendendo textos, imagens, links e vídeos publicados nas páginas durante o ano de 2018. Os documentos coletados foram referentes ao 
período de um ano, de 1 (um) de janeiro de 2018 a 31 (trinta e um) de dezembro de 2018. O período foi delimitado com a finalidade de abarcar um ciclo completo de publicações, diminuindo a interferência de pautas temporárias, como as eleições ou as datas comemorativas de final de ano, por exemplo. Além disso, o lapso de tempo entre a publicação e a coleta de dados é importante, visto que as publicações já adquiriam certa estabilidade do número de interações, permitindo a comparação dos dados entre as páginas. Considerando a dinâmica das mídias sociais, existe uma tendência de grande movimentação logo que são postadas, bem como de estagnação após alguns dias, o que permite uma segurança para a comparação dos dados entre as páginas. A coleta de documentos e informações foi realizada sem a utilização de softwares específicos, no período de 04 a 18 de fevereiro de 2019. Para cada publicação foi preenchida uma ficha individual com os seguintes elementos: data da postagem, natureza da postagem (link, imagem, vídeo etc), tema principal, pilar (Institucional, atribuição, outros), texto inserido na publicação, texto descritivo, curtidas, comentários, compartilhamentos, visualização (no caso de vídeos), e eventual direcionamento a links externos.

Inicialmente foi feita uma leitura exploratória dos materiais com o objetivo de delimitar o corpus de pesquisa, elencar previamente as categorias de análise e elaborar as hipóteses e objetivos. Assim, inicialmente os materiais foram classificados por sua natureza (vídeo, imagem, links ou compartilhamentos de outras páginas), que são categorias comuns nas duas páginas analisadas. As postagens foram ainda agrupadas em temáticas principais. Como as publicações das duas páginas possuem conteúdos distintos, as categorias temáticas também foram distintas.

A segunda etapa da pesquisa trata-se da exploração do material que, para Laurence Bardin (2016, p. 132), constitui a “aplicação sistemática das decisões tomadas”. Nesta etapa, os dados obtidos foram realocados, a fim de aferir algumas conclusões por meio da comparação. Assim, as postagens foram elencadas por pilar: estritamente institucional, postagens de atribuições e outros. Foram analisados ainda os dados de interações dos usuários nas duas páginas.

Sobre a classificação dos documentos, André Cellard (2008) destaca que os documentos escritos podem se dividir em públicos e privados. Enquanto os documentos públicos se dividem em arquivos públicos (ex. arquivos governamentais, arquivos do 
estado civil, arquivos de natureza notarial, etc) e documentos públicos não arquivados (ex. jornais, revistas, periódicos, publicidade, anúncios, etc). Os privados se dividem em arquivos privados (ex. documentos de organizações políticas, sindicatos, igrejas, empresas, etc) e documentos pessoais (ex. diários, correspondências, documentos de família, etc). Assim, as postagens nas páginas oficiais no Facebook das instituições analisadas podem ser consideradas documentos públicos não arquivados, conforme a divisão de Cellard (2008).

\section{Principais resultados}

\subsection{O Ministério Público Federal no Facebook}

As disposições sobre o Ministério Público se encontram principalmente no Capítulo IV, Seção I, da Constituição Federal (CF/88). A Constituição estabelece em seu art. 127, $§ 2^{\mathbf{o}}$ que ao Ministério Público é assegurada autonomia funcional e administrativa, não se subordinando diretamente a nenhum dos outros poderes da federação. Além disso, a CF/88 prevê a independência funcional como princípio institucional do MP. Atualmente o Ministério Público organiza-se em dois eixos: Ministério Público da União (MPU) e Ministério Público dos Estados (MPE), que corresponde às unidades da federação.

A página oficial do MPF no Facebook conta, no momento em que os dados foram coletados para a pesquisa, com 496.520 seguidores, e a descrição da instituição no Facebook apenas remete ao site oficial na internet: www.mpf.mp.br. Ao longo do ano de 2018 foram feitas 426 postagens na página do MPF, uma média de 1,16 postagens por dia. Com relação à natureza das publicações, 368 (86,38\%) foram de imagens com ou sem texto; 29 (6,81\%) links externos sem imagens vinculadas; 24 (5,63\%) vídeos; e 5 (1,17\%) compartilhamentos de outras páginas do Facebook. Verifica-se assim, uma predominância de postagens com imagens, em detrimento de outros formatos.

A primeira divisão do conteúdo coletado foi feita a partir do tema principal das publicações. Como o MPF tem atuações em amplos setores, as categorias também foram variadas, com 20 temáticas centrais diferentes. 
Gráfico 1 - Dados de postagens na página oficial do MPF no Facebook, por temas, em 2018.

\section{Postagens do MPF no Facebook - por tema (2018)}

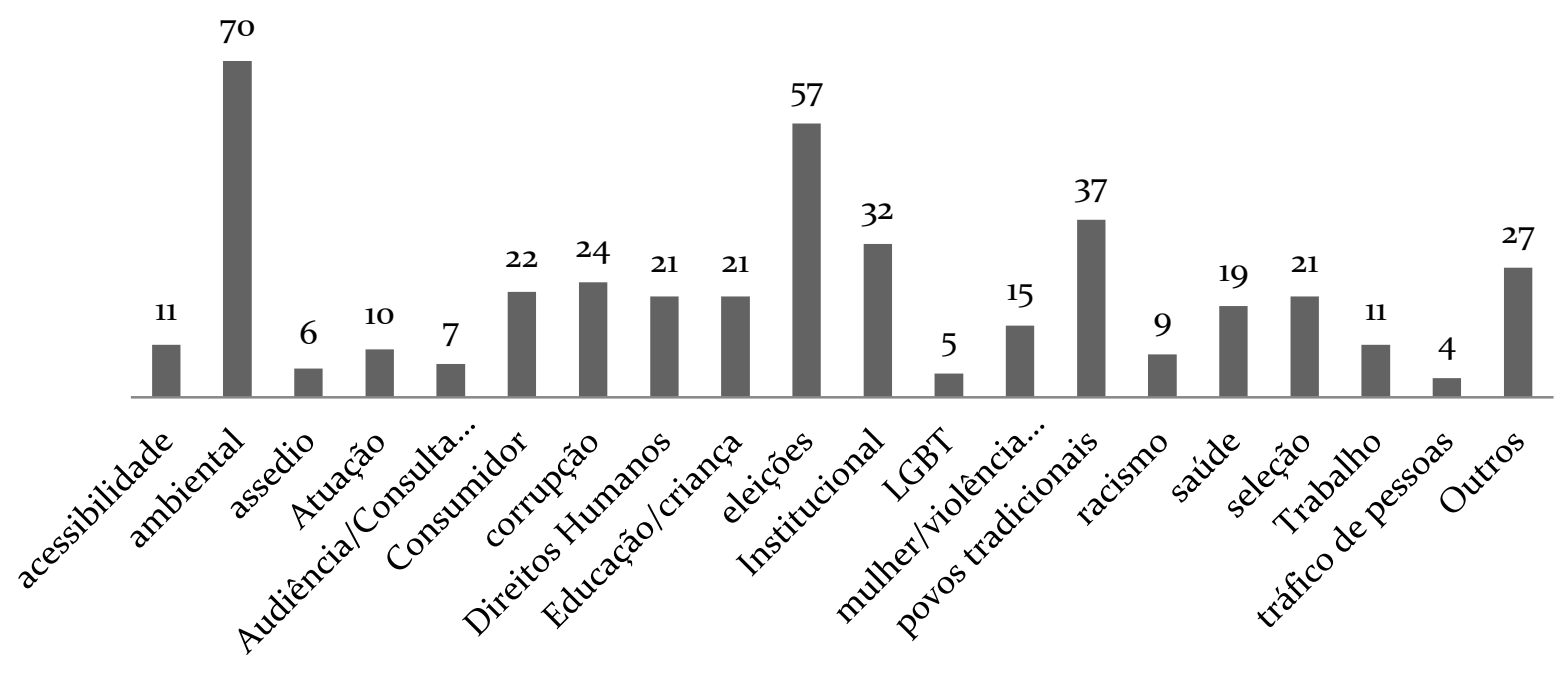

Fonte: Facebook (2018), gráfico elaborado pela autora.

Foram categorizados como "atuação" as postagens que se referem diretamente à divulgação de atividades do MP, com a utilização de verbos que indicam atividades do MP, como por exemplo: "MPF vai acompanhar" e "MPF recomenda". Como “institucional” foram designadas as postagens que remetem à estrutura do Ministério Público, ao seu reforço como instituição organizada e atuante, em menção direta às suas estruturas e nome da instituição. As postagens de "seleção", foram categorizadas separadamente por direcionarem-se a um público específico, visto tratar-se de divulgação de processos seletivos vinculados à instituição. Ademais, a categoria “assédio" engloba as postagens referentes tanto ao assédio moral, quanto assédio sexual.

O tema corrupção se apresenta como uma categoria temática, ainda que integre um índice relativamente baixo de postagens diretamente relacionadas ao tema, representando cerca de $5 \%$ do total. Analisando o gráfico, destaca-se a predominância de postagens relacionadas ao tema ambiental (16,32\%), seguidas das postagens sobre as eleições $(13,29 \%)$. Em terceiro lugar destacam-se as postagens relacionadas a povos tradicionais (8,32\%): quilombolas, indígenas, ciganos, dentre outros. 
A predominância de temas diferenciados possui relação com as novas atribuições conferidas ao MP após a Constrição de 1988, em que a instituição passou a incorporar novas funções, englobando atividades como controle da atividade policial, a supervisão da pena privativa de liberdade e a proteção e garantia dos direitos difusos, coletivos e individuais homogêneos, atividades que transcendem a tradicional atuação na esfera criminal. Assim, as postagens de tema ambiental e proteção de povos tradicionais, dentre diversas outras categorias, podem ser atribuídas às novas competências do MP conferidas pela $\mathrm{CF} / 88$. As eleições aparecem em destaque tanto em função desta nova prerrogativa, quanto também em função da agenda eleitoral, visto que em 2018 ocorreram eleições para cargos do executivo e legislativo, federal e estadual.

As interações na página também são importantes elementos de aferição sobre a percepção dos receptores da informação. A média de curtidas por postagem é de 352, a média de comentários é de 49 por postagem, e a média de compartilhamentos é de 297 por cada postagem realizada. Com relação às interações na página, verifica-se que ainda que a média de curtidas e comentários seja menor que as verificadas na página da Polícia Federal, como será explanado a seguir, a média de compartilhamentos das postagens do MPF é maior, indicando que os usuários entendem que o conteúdo é relevante para compartilhar em suas páginas pessoais, ainda que muitas vezes não façam comentários diretamente na página. 
Gráfico 2 - Dados de médias de interações nas postagens na página oficial do MPF no Facebook, por temas, em 2018.

\section{Média de interações de usuários na página do MPF - Por tema (2018)}

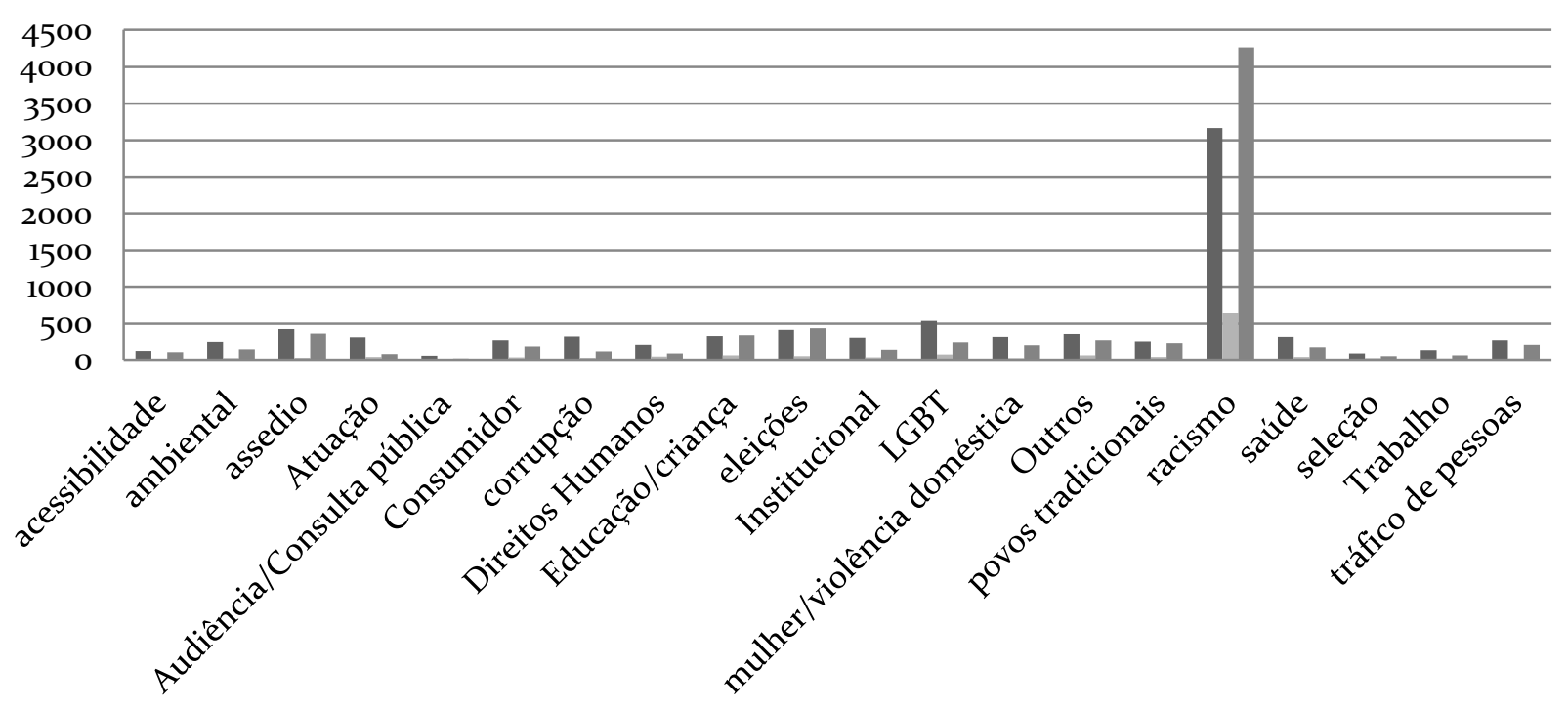

Fonte: Facebook (2018), gráfico elaborado pela autora.

Com relação às interações por temáticas, verifica-se que a média tanto de curtidas, quanto de comentários e compartilhamentos, é manifestamente maior nas publicações sobre racismo, se comparados com a média de interações das postagens de outras temáticas, inclusive de publicações institucionais. Ainda que as publicações sobre racismo ou temas correlatos tenham uma média de respostas na rede social maior que de outros tipos de postagens, a grande diferença no gráfico provavelmente se deve ao conteúdo publicado no dia 13 de abril de 2018, que alcançou altíssimos níveis de interação, se comparadas às médias da página. A publicação em questão tratava de uma notícia sobre a denúncia da Procuradoria Geral da República (PGR) a Jair Bolsonaro pelo crime de racismo, e alcançou cerca de 19 mil curtidas, 4800 comentários e 18.852 compartilhamentos.

No que tange à análise de conteúdo, destaca-se que as publicações na página oficial do MPF no Facebook possuem a característica predominante de divulgação de informações à comunidade sobre algum tema específico já estabelecido na Constituição 
ou que constitui orientação consolidada da Procuradoria Geral da República. Assim, um aspecto de destaque são as perguntas inseridas tanto na imagem quanto no texto de descrição, como "Você sabia?”, “Já ouviu falar?”, ou com perguntas específicas sobre o conteúdo da publicação. Em seguida, é feita uma breve explicação do assunto, seja no texto com a imagem, seja no texto de descrição. Podemos mencionar alguns exemplos:

- 21/11/2018 - "Já ouviu falar em Viaduto Vegetado? É uma passagem de fauna para preservar espécies de animais. No Brasil, o primeiro será no RJ.”

- 28/11/2018 - "Você sabia que o Brasil é um dos países maior número de cesarianas? Ação do MPF pede regulamentação dos serviços obstétricos realizados por consultórios médicos e hospitais privados.”

- 10/12/2018 - "O que é a declaração Universal de Direitos Humanos? É um documento que ajudou a regular direitos básicos, como condições dignas de trabalho, liberdade, igualdade, saúde, educação e direito de propriedade.”

As publicações com imagens na página do MPF possuem grande quantidade de texto, principalmente se comparadas às postagens da $\mathrm{PF}$, reforçando o caráter informativo das publicações. Além disso, como publicações com muito texto podem se tornar cansativas nas mídias sociais, que possuem uma dinâmica de visualização rápida, a utilização de perguntas como "Você Sabia?" intentam dar mais proximidade ao público, visando instigar o usuário a interagir com a página.

Este tipo de publicação reforça as atribuições constitucionais do MPF, ainda que muitas vezes não trate diretamente do MPF como agente promotor das melhorias ou da fiscalização mencionadas. As publicações informativas visam reforçar a atuação do MPF como instituição responsável pela proteção e garantia dos direitos difusos, coletivos e individuais homogêneos, atribuição relativamente recente na história do MPF brasileiro, e singular se comparado às atribuições de outros MPs no mundo. (RIBEIRO, 2017).

Praticamente todas as postagens possuem o "Pra cego ver" apresentada com uma hashtag, que se refere a um "projeto de disseminação da cultura da acessibilidade nas redes sociais e tem por princípio a Audiodescrição de imagens para apreciação das pessoas com deficiência visual”, conforme a apresentação na própria página do projeto 
no Facebook: Pra Cego Ver. Assim, as imagens publicadas na página do MPF possuem uma descrição do seu conteúdo, para facilitar o acesso de deficientes visuais que utilizam programas de leitura automática. Essa estratégia também reforça o posicionamento do MPF como defensor dos interesses sociais e individuais indisponíveis, conforme preceitua a Constituição de 1988. Ademais, as postagens quase não utilizam outras hashtags, diferente da página da PF, que faz amplo uso do artifício.

\subsection{A Polícia Federal no Facebook}

O Departamento da Polícia Federal é um órgão atualmente subordinado ao Ministério da Justiça e Segurança Pública e sua função e organização estão previstas no art. 144, §1º̄, da Constituição Federal de 19883. A página oficial da Polícia Federal - PF no Facebook contava com 2.732.926 seguidores no momento em que foi realizada a coleta de dados, e sua descrição na mídia social também remete ao site oficial da instituição: www.pf.gov.br. No entanto, a página contém ainda a data de criação do órgão, missão, informações gerais sobre a sua criação, bem como um link direto para envio de mensagens.

Ao longo do ano de 2018, foram feitas 569 postagens na página oficial da PF no Facebook, uma média de 1,55 postagens por dia, uma média um pouco maior se comparada à página do MPF. Com relação à natureza das publicações, 501 (88,05\%) foram imagens, com ou sem texto; 67 (11,78\%) foram vídeos; e apenas 1 (0,18\%) link de site externo, sem imagem vinculada. Verifica-se assim, uma predominância de publicações com imagens, em percentual semelhante ao encontrado na página do MPF. No entanto, na página da PF não foram compartilhadas publicações de outras páginas do Facebook.

\footnotetext{
${ }^{3} \S 1$ o A polícia federal, instituída por lei como órgão permanente, estruturado em carreira, destina-se a: I - apurar infrações penais contra a ordem política e social ou em detrimento de bens, serviços e interesses da União ou de suas entidades autárquicas e empresas públicas, assim como outras infrações cuja prática tenha repercussão interestadual ou internacional e exija repressão uniforme, segundo se dispuser em lei; II - prevenir e reprimir o tráfico ilícito de entorpecentes e drogas afins, o contrabando e o descaminho, sem prejuízo da ação fazendária e de outros órgãos públicos nas respectivas áreas de competência; III exercer as funções de polícia marítima, aérea e de fronteiras; IV - exercer, com exclusividade, as funções de polícia judiciária da União.
} 
Além disso, o percentual de vídeos da PF (11,78\%) é bem maior se comparado ao índice de vídeos do MPF (1,17\%), indicando maior preferência da PF por este tipo de publicação. Ao verificarmos o teor dos vídeos, no entanto, constata-se que muitos deles são apenas institucionais, em que o mesmo vídeo foi publicado em diversas ocasiões, apenas informando sobre alguma atividade da PF naquele dia, como operações deflagradas, ou cumprimento de mandados de prisão. Esses vídeos institucionais possuem a descrição "PF nas Ruas. \#EuConfioNaPF", com trechos genéricos de carros de PF em movimento. Assim, a utilização de vídeos pela PF se apresenta como uma estratégia para atrair a atenção para as atividades do dia, em que o teor se encontra no texto de descrição, e não necessariamente atrair a atenção para o conteúdo do vídeo em si.

A primeira categorização das postagens foi feita a partir do seu tema principal, de acordo com o texto da imagem e texto de descrição da publicação. Ainda que a PF tenha realizado mais postagens ao longo do ano de 2018 do que o MPF, inicialmente elas foram divididas em menos grupos temáticos, um total de 13 categorias.

Para fins de categorização, foi considerado o tema principal da postagem, ponderando a imagem e texto de descrição, ainda que nela contenham outros elementos subsidiários. Uma ressalva deve ser feita com relação às postagens com a temática " $P F$ em Ação" ou "PF nas Ruas", que também podem ser referentes a operações realizadas pela polícia. No entanto, como o título dessas publicações foi especificamente alocado pela própria instituição, essa denominação foi considerada para a primeira categorização nesta pesquisa. O gráfico a seguir demonstra as temáticas principais do conteúdo na página da PF no Facebook: 
Gráfico 3 - Dados de postagens na página oficial da PF no Facebook, por temas, em 2018.

\section{Postagens da PF no Facebook - por tema (2018)}

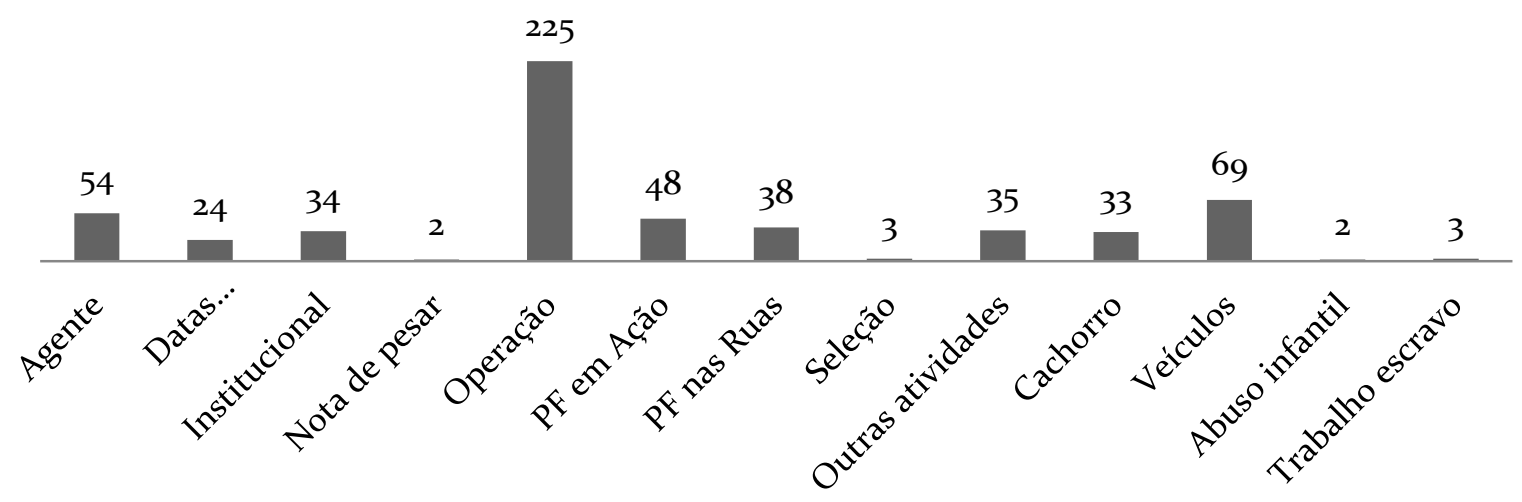

Fonte: Facebook (2018), gráfico elaborado pela autora.

As postagens categorizadas como "agentes”, "veículos" ou "cachorros” não se referem a conteúdos com essas temáticas, mas referem-se a postagens que trazem diretamente a imagem de algum desses três elementos, como imagens dos agentes em operação ou imagens de cachorros da instituição com a finalidade de gerar empatia do público. As postagens com esses 3 elementos especificamente (cachorros, agentes e veículos) não contém textos na publicação diretamente, mas apenas o texto descritivo da publicação. Não indicam atividades específicas da PF mas normalmente são acompanhadas de frases genéricas em sua descrição como "bom dia" e "bom final de semana”, visando apenas o reforço institucional e não necessariamente a transmissão de informações sobre as atividades da PF. Assim, as publicações podem conter imagens de agentes que indicam estar em serviço junto com veículos da PF, agentes com cachorros, cachorros ao lado de veículos da PF, imagens com apenas um desses três elementos, dentre outros exemplos. As postagens consideradas na categoria "Institucional" remetem diretamente à $\mathrm{PF}$ no texto, reforçando a imagem da instituição.

Observa-se um destaque para publicações de Operações da PF, que representam $37,48 \%$ do total, seguida das postagens com veículos em 12,11\% do total de postagens. Em terceiro lugar encontram-se as postagens com agentes da PF, em 9,47\% do conteúdo total. Ainda que o tema da corrupção não se apresente como temática principal na 
primeira categorização, como ocorre na página do MP, o assunto integra várias das publicações de outras categorias. Assim, o conteúdo coletado foi re-categorizado de acordo com os objetos principais das operações ou atividades da PF publicadas na rede social, conforme a figura abaixo:

Gráfico 4 - Dados de postagens na página oficial da PF no Facebook, por objeto das atividades, em 2018.

\section{Postagens da PF no Facebook - por objeto das atividades (2018)}

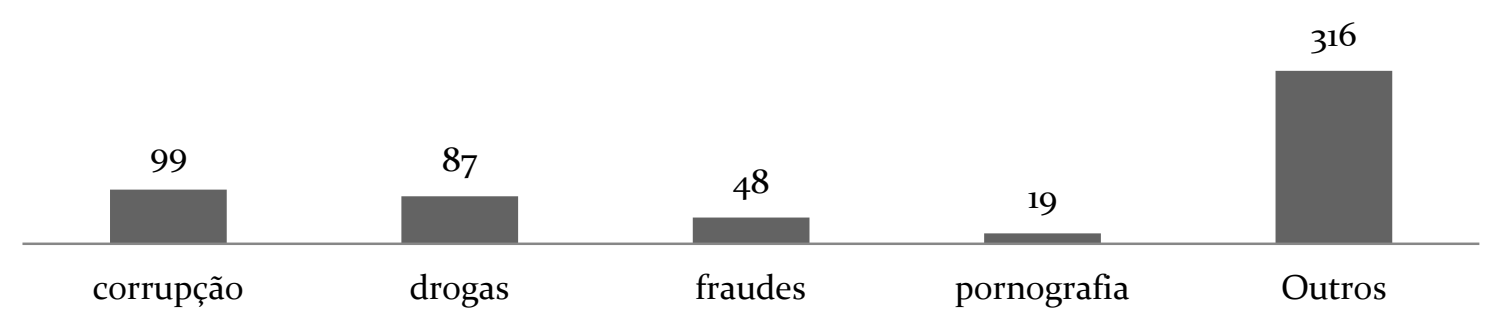

Fonte: Facebook (2018), gráfico elaborado pela autora.

Assim, dentre os principais objetos das atividades deflagradas pela PF, destaca-se que a corrupção é uma das principais categorias abordadas na página oficial no Facebook, representando $17 \%$ do total de publicações. Logo após estão as publicações com foco na apreensão de drogas e combate ao tráfico, com $15 \%$ do total de postagens. A categoria "Outros" engloba as postagens meramente institucionais que não representam operações diretas do órgão no combate à criminalidade (como fotos de agentes, por exemplo), datas comemorativas, ou categorias com menos expressividade numérica que as demais.

Com relação às interações dos usuários, a média geral de curtidas por postagem na página da PF é de 1113, a média de comentários é de 74 , e a média de compartilhamentos é de 171. Sobre as interações dos usuários com a página, verifica-se que o número médio de curtidas e comentários por postagem é bem maior que o verificado na página do MPF, indicando que os usuários se relacionam mais na página da PF. No entanto, a média de compartilhamentos é menor, indicando que o conteúdo 
se mostra menos relevante aos usuários do que os conteúdos da página do MPF para que compartilhem em sua página pessoal. Ao aferirmos a média de interações de acordo com cada temática, temos o gráfico a seguir:

Gráfico 5 - Dados de médias de interações nas postagens na página oficial da PF no Facebook, por temas, em 2018.

\section{Média de interações de usuários na página da $\mathrm{PF}$ - por tema (2018)}

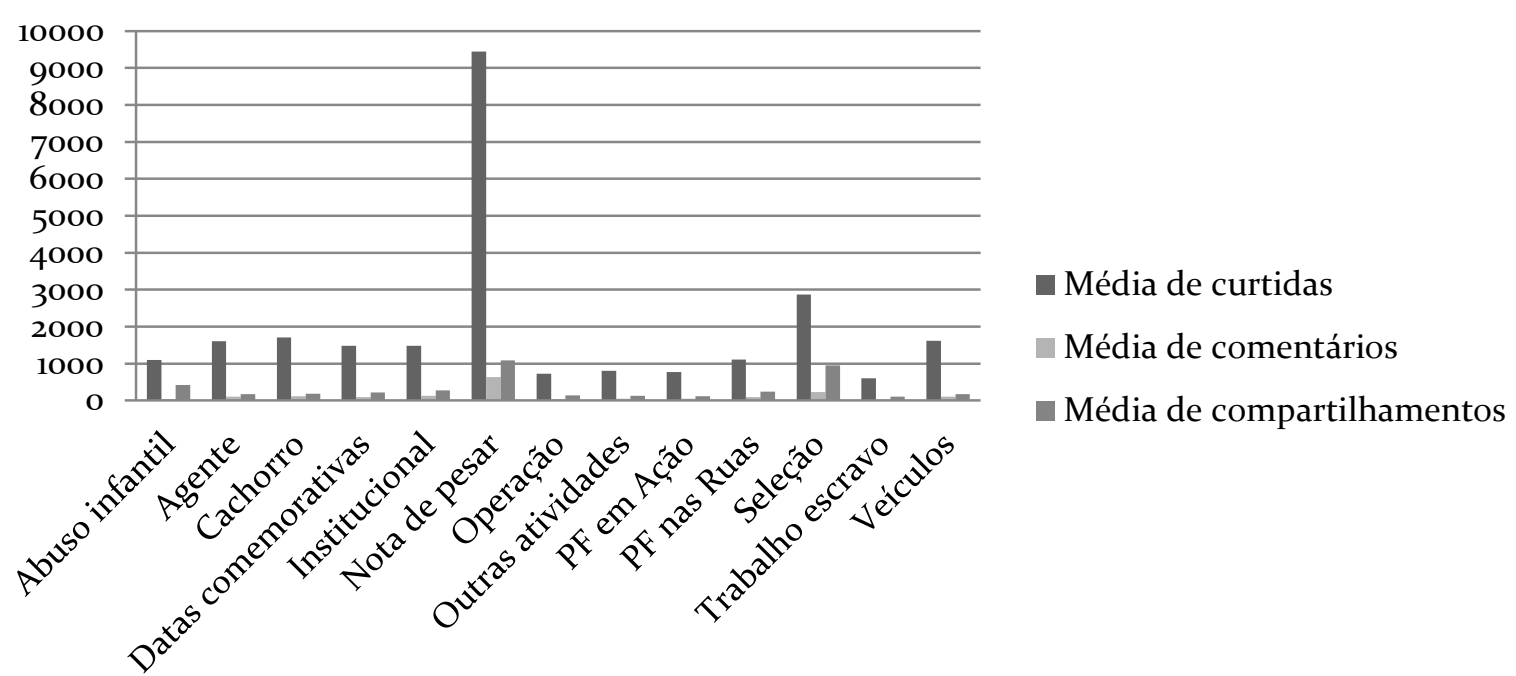

Fonte: Facebook (2018), gráfico elaborado pela autora.

Verifica-se no gráfico 5 que a média de interações em postagem de notas de pesar é muito maior que a média de interações em outros tipos de publicações, ainda representem um baixo número em comparação aos outros temas (apenas 2 publicações), evidenciando que o público se solidariza e se identifica com os agentes da instituição. Como será destacado, a PF possui como uma de suas estratégias o reforço de identificação dos usuários com os valores da instituição, com o uso de hashtags "SomosTodosPF", dentre outras. Um dos resultados desta estratégia de identificação é a grande quantidade de interações em notas de pesar, por exemplo. Em seguida verificase grande interação também nas postagens sobre seleções. As seleções na página da PF se referem principalmente à divulgação de informações sobre concursos para ingressar 
na instituição, o que explica a grande interação nas publicações sobre o tema por parte dos chamados "concurseiros" e seus conhecidos.

Com relação ao conteúdo, uma forte característica das publicações na página oficial da PF no Facebook é a divulgação de operações deflagradas e demais atividades policiais, como apreensão de drogas e cumprimentos de mandados de prisão. As postagens possuem textos mais curtos em relação ao conteúdo publicado na página do MPF, e possuem o condão de informar principalmente sobre as atividades desenvolvidas pela PF. Raramente encontram-se informações gerais que não estejam vinculadas às atividades policiais rotineiras da instituição. Além disso, 57\% das postagens remetem os usuários ao site oficial da PF, que contem informações mais detalhadas sobre as operações e atividades realizadas. A título de comparação, na página do MPF apenas 21\% das postagens remete o leitor ao site oficial da Instituição.

As publicações com imagens estritamente institucionais, com agentes, veículos e cachorros não remetem ao site oficial da PF, e possuem o condão de gerar empatia e identificação com a instituição. Além disso, a PF faz amplo uso de hashtags em suas publicações, como por exemplo "EuConfionaPF", "BoaTarde”, "Brasil”, dentre outras. Os nomes das operações realizadas também aparecem com o uso de hashtags. As hashtags podem ser colocadas no início ou final da frase, ou mesmo no meio da oração, seja no texto de referência ou na própria imagem da publicação, como nos exemplos a seguir:

- 16/o9/2018 - "\#Perícia sendo realizada em uma agência dos Correios em Porto de Trombetas/PA. Um bom \#domingo \#Brasil. A PF não pára!"

- 23/o9/2018 - “Um ótimo \#domingo \#Brasil!"

- 02/10/2018 - "Nosso \#cão \#Elvis, do \#K9, nos dando um grande auxilio na apreensão de $36 \mathrm{~kg}$ de \#drogas no \#Acre."

- 19/12/2018 - “\#PFemAção: Estamos cumprindo 8 mandados de busca e apreensão expedidos pelo STF. A ação tem como objetivo investigar o recebimento de vantagens indevidas por um ex prefeito, atualmente exercendo o cargo de Ministro.”

A utilização de hashtags possui a finalidade de facilitar a busca de informações na rede sobre o seu conteúdo, como também de gerar empatia do público. Assim, o uso 
da hashtag "Brasil", por exemplo, além de reproduzir a publicação da PF quando os usuários pesquisam sobre o tema na rede social, também reforça o posicionamento de que a PF é essencial para o país.

\section{3·3 Relações entre as páginas: MPF e PF no Facebook}

Após as primeiras categorizações das postagens, serão explanados alguns resultados comparativos entre os dados das duas páginas analisadas. Com relação à distribuição das postagens entre os meses, verifica-se uma regularidade de frequência, tanto do MPF quanto da PF, conforme gráfico abaixo:

Gráfico 6 - Dados de distribuição das postagens nas páginas oficiais da PF e do MPF no Facebook, por mês, em 2018.

\section{Distribuição de postagens por mês - MPF x PF (2018)}

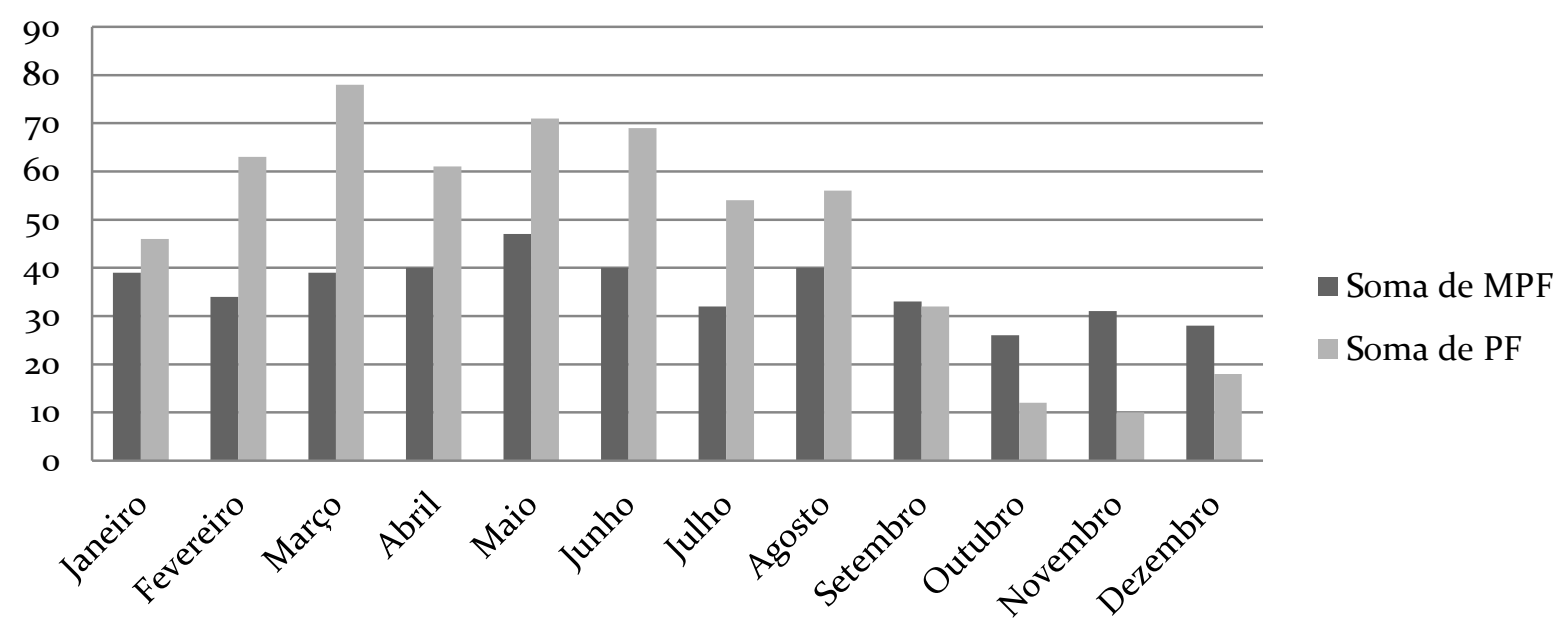

Fonte: Facebook (2018), gráfico elaborado pela autora.

Contudo, ainda que as duas instituições publiquem conteúdos assiduamente em todos os meses, verifica-se que o MPF preserva um padrão de número de postagens mais uniforme que a PF. Enquanto a variação do número de postagens entre os meses na página da MPF é de no máximo 21, na página da PF essa diferença chega a 68, indicando 
maior oscilação nesta última. Assim, ainda que a PF tenha realizado mais postagens ao longo do ano de 2018, as publicações na página do MPF apresentam maior regularidade.

Após a primeira categorização das postagens das páginas do MPF e PF no Facebook, conforme exposto acima, uma segunda categorização foi feita, de acordo com a finalidade institucional das postagens. Assim, as postagens foram divididas em "Institucionais", de “Atribuição”, ou “Outros”. Neste momento, foram consideradas como Institucionais as postagens em que o texto e a imagem visam reforçar a diretamente a imagem da Instituição, como fotos dos agentes, veículos, atividades desenvolvidas diretamente pelos órgãos, esclarecimentos sobre seus serviços etc. Foram consideradas como de Atribuição as postagens relacionadas às atribuições constitucionais de cada órgão, que também possuem a finalidade de reforçar a imagem da instituição, mas comunicando aos receptores da mensagem que o órgão está cumprindo suas funções institucionais com êxito. Na categoria "Outros” foram incluídas as publicações com conteúdo de seleção de estagiários, concursos públicos, concursos de artigos, datas comemorativas que não se relacionam diretamente à atividade do órgão.

Gráfico 7 - Dados de distribuição das postagens nas páginas oficiais da PF e do MPF no Facebook, por pilar, em 2018.

\section{Distribuição de postagens por pilar (2018)}

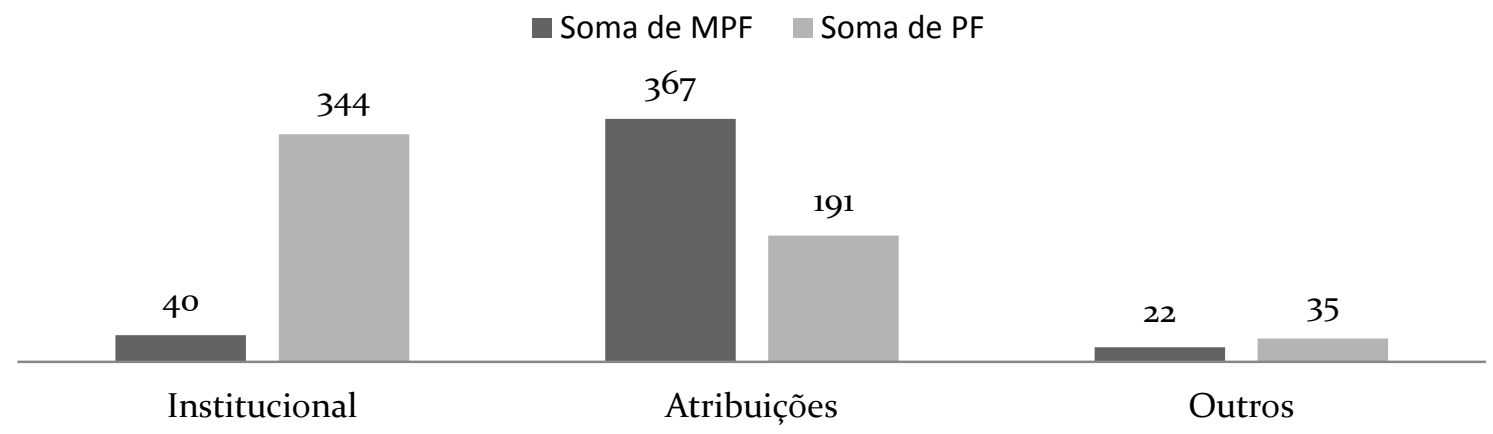

Fonte: Facebook (2018), gráfico elaborado pela autora. 
Depreende-se do gráfico que ambas as instituições, MPF e PF, atribuem grande ênfase às postagens de cunho Institucional ou de reforço de Atribuições, de forma que apenas cerca de $5 \%$ das postagens não se enquadrou em algum dos dois pilares, nas duas páginas analisadas. Assim, constata-se que há grande interesse de ambas as instituições em reforçar seu poder simbólico com a utilização de instrumentos de comunicação, como as mídias sociais. Ademais, observa-se ainda uma clara diferença entre as abordagens das duas Instituições. Enquanto a maioria das publicações da PF possui cunho estritamente institucional, relacionadas à estrutura da PF, as postagens do MPF em sua maioria intentam reforçar suas atribuições Constitucionais.

$\mathrm{Na}$ página da $\mathrm{PF}$, as postagens institucionais são geralmente de agentes, cachorros que participam das operações e veículos. Essas postagens normalmente não possuem texto nas imagens, apenas o texto descritivo e possuem descrições com textos que geram empatia, como "Bom Dia!", “Bom Domingo”, “Boa Sexta”. Nessas postagens os textos não apresentam informações sobre atividades desenvolvidas, e não apresentam linguagem técnica, bem como raramente vinculam links externos. A utilização de hashtags nessas publicações também é amplamente utilizada, assim como nas demais postagens. As principais hashtags utilizadas na página são a "SomosTodosPF" e “EuConfionaPF”, que visam gerar identificação dos usuários com a instituição e reforçar seu poder simbólico. Além disso, nas publicações institucionais também são utilizadas frases motivacionais de autores famosos. As hashtags "disciplina" e "BonsEstudos" também são utilizadas, acenando aos usuários que pretendem ingressar no corpo de funcionários por meio de concurso público.

Já as postagens do MPF que priorizam o cumprimento de suas atribuições normalmente apresentam um texto informativo sobre questões relevantes, reforçando o posicionamento da instituição como defensora do regime democrático e dos interesses sociais e individuais indisponíveis, conforme preceitua a Constituição. A prioridade das publicações na página do MPF é de informar a população sobre seus direitos e deveres, bem como de outros assuntos relevantes de competência do MPF. Os textos usualmente apresentam perguntas que são respondidas em seguida, que possuem o condão de aumentar a interatividade com o publico. 


\section{Considerações finais}

Ainda que as mídias sociais compreendam algumas limitações, como público limitado, elas se apresentam como uma importante ferramenta de análise, principalmente pela possibilidade de aferição das interações com as publicações realizadas. A coleta dos documentos foi feita nas páginas oficiais do MPF e PF, referente ao período de um ano (2018). Após, os dados foram categorizados e posteriormente comparados.

Inicialmente, destaca-se que as duas instituições dispõem de abordagens diferentes nas mídias sociais, ainda que integrem a mesma operação com grande apelo midiático (operação Lava Jato). Assim, enquanto a Polícia Federal prioriza publicações institucionais, mencionando diretamente a instituição e seus recursos institucionais, como capacitação dos agentes e veículos, o Ministério Público prioriza destacar assuntos relacionados às suas atribuições constitucionais, principalmente aquelas relacionadas à defesa dos interesses sociais. No entanto, ambas as instituições priorizam publicações institucionais e de reforço de suas atribuições constitucionais, em detrimento de temas mais amplos, o que indica o intuito de ratificar seu poder simbólico frente ao público. Essa diferença pode ser estritamente técnica ou mesmo decorrente da diferença entre suas atribuições constitucionais, o que pode ser averiguado em estudos posteriores sobre o tema.

Além disso, o tema da corrupção é abordado nas duas páginas analisadas, mesmo que apareçam com frequências diferentes. Ainda que a PF não destaque a corrupção como principal tema de suas postagens, o assunto permeia $17 \%$ do total de publicações, representando que é de grande relevância em sua página na rede social. É importante verificarmos se esse índice reflete o percentual semelhante do total de atividades desenvolvidas pela PF rotineiramente, ou se representa apenas uma escolha no momento da divulgação nas redes sociais, o que pode ser objeto de estudos posteriores. De outro norte, ainda que a corrupção apresente destaque nas publicações do MPF, constituindo-se como uma categoria temática inicial, o percentual de publicações sobre o tema é relativamente baixo (5\%) indicando que não foi prioridade de divulgação no Facebook durante o ano de 2018. 
Com relação à interação dos usuários da mídia social, a média de postagens, curtidas e comentários na página da PF são maiores que as verificadas na página do MPF. No entanto, a média de compartilhamentos das publicações é maior na página do MPF, indicando que os usuários consideram a informação mais relevante para compartilhar em sua páginas pessoais e com seus amigos. Isso decorre do caráter predominante do conteúdo na página da MPF, que possui o condão de transmitir informações sobre temas relevantes para a população.

Assim, este estudo não intenta esgotar as reflexões sobre a comunicação das instituições no âmbito das mídias sociais, mas elucidar alguns pontos necessários à compreensão da utilização do ciberespaço por instituições da burocracia estatal, iluminando aspectos deste recente fenômeno, a fim de fomentar mais estudos sobre o tema.

\section{Referências}

BARDIN, L. Análise de conteúdo. Lisboa: Ed. 70, 1979.

BAUER, M.; GASKELL, G. (ed.). Pesquisa qualitativa com texto, imagem e som: um manual. Petrópolis, RJ: Vozes, 2002.

BOURDIEU, P. O poder simbólico. 11플 Edição. Rio de Janeiro: Bertrand Brasil, 2007.

CELLARD, A. et al. A análise documental.In: POUPART, J. et al.A pesquisa qualitativa: enfoques epistemológicos e metodológicos. Petrópolis: Vozes, 2008.

FRAGOSO, S.; RECUERO, R.; AMARAL, A. Métodos de pesquisa para internet. Porto Alegre: Sulina, 2011.

FEIJÓ, C.; VALENTE, E. As estatísticas oficiais e o interesse público. Bahia Análise \& Dados, Salvador, v. 15, n. 1, p. 43-54, jun. 2005.

Disponível em: <http://www.icad.puc-rio.br/cfeijo/pdf/artigofeijo_e_valente.pdf>. Acesso: 17/02/2019.

LEMOS, C. R. F.; BARROS, A. T. Lutas simbólicas na arena midiática: o poder de agência do Ministério Público e as controvérsias sobre a PEC 37. Opin. Publica. 2016, vol.22, n.3 pp.702-738. Disponível em: $<$ http://www.scielo.br/scielo.php?script=sci_arttext\&pid=So10462762016000300702\&lng=pt\&nrm=iso $>$. 
MINISTÉRIO PÚBLICO FEDERAL. “Operação Lava Jato”. Disponível em: <http://www.mpf.mp.br/grandes-casos/lava-jato>. Acesso em 15 de dezembro de 2018.

PINOTTI, M. C. (org.). Corrupção: Lava Jato e Mãos Limpas. 1ª̨Ed.. São Paulo: Portfolio-Penguin, 2019.

POLÍCIA FEDERAL. “Op. Lava Jato 3 anos”. Disponível em: http://www.pf.gov.br/imprensa/lava-jato. Acesso em 15 de dezembro de 2018.

PRA CEGO VER. Post do Facebook. 8 de outubro de 2016. Disponível em: $<$ https://www.facebook.com/PraCegoVer/posts/tire-todas-as-suas-d\%C3\%BAvidassobre-o-projeto-pracegover-pra-iniciar-um-aviso-impor/1282608151769692/>. Acesso em 27 de fevereiro de 2019.

RAMOS, M. P. Métodos quantitativos e pesquisa em Ciências Sociais: lógica e utilidade do uso da quantificação nas explicações dos fenômenos sociais. Mediações, Londrina, v. 18, no1, p.55-65, jan/jun 2013.

RIBEIRO, L. M. L. Ministério Público: Velha instituição com novas funções?. Revista Crítica de Ciências Sociais, 113, setembro 2017.

SÁ-SILVA, J. R.; ALMEIDA, C. D.; GUINDANI, J. F. Pesquisa documental: pistas teóricas e metodológicas. Revista Brasileira de História \& Ciências Sociais, Ano n. 1, 2009 .

VEIGA, I. R. Coberturas jornalísticas e construção de reputação institucional: A representação da Polícia Federal na imprensa e seus reflexos identitários. Dissertação de mestrado: Universidade Federal de Juiz de Fora Mestrado em Comunicação e Sociedade. 2009. 